\title{
Cross-Talk Between Extracellular Matrix and Skeletal Muscle: Implications for Myopathies
}

\author{
Khurshid Ahmad, Sibhghatulla Shaikh, Syed Sayeed Ahmad, Eun Ju Lee and Inho Choi * \\ Department of Medical Biotechnology, Yeungnam University, Gyeongsan, South Korea
}

\section{OPEN ACCESS}

Edited by:

Feng Chen,

Peking University,

China

Reviewed by:

Nan Jiang,

Peking University Hospital of Stomatology, China

Francisco Villarreal,

University of California,

San Diego, United States

${ }^{*}$ Correspondence:

Inho Choi

inhochoi@ynu.ac.kr

Specialty section: This article was submitted to Translational Pharmacology,

a section of the journal

Frontiers in Pharmacology

Received: 17 November 2019 Accepted: 04 February 2020

Published: 28 February 2020

Citation:

Ahmad K, Shaikh S, Ahmad SS, Lee EJ and Choi I (2020) Cross-

Talk Between Extracellular

Matrix and Skeletal Muscle:

Implications for Myopathies.

Front. Pharmacol. 11:142. doi: 10.3389/fphar.2020.00142
Skeletal muscle (SM) comprises around $40 \%$ of total body weight and is among the most important plastic tissues, as it supports skeletal development, controls body temperature, and manages glucose levels. Extracellular matrix (ECM) maintains the integrity of SM, enables biochemical signaling, provides structural support, and plays a vital role during myogenesis. Several human diseases are coupled with dysfunctions of the ECM, and several ECM components are involved in disease pathologies that affect almost all organ systems. Thus, mutations in ECM genes that encode proteins and their transmembrane receptors can result in diverse SM diseases, a large proportion of which are types of fibrosis and muscular dystrophy. In this review, we present major ECM components of SMs related to muscle-associated diseases, and discuss two major ECM myopathies, namely, collagen myopathy and laminin myopathies, and their therapeutic managements. A comprehensive understanding of the mechanisms underlying these ECM-related myopathies would undoubtedly aid the discovery of novel treatments for these devastating diseases.

Keywords: collagen, extracellular matrix, laminin, myopathy, skeletal muscle

\section{INTRODUCTION}

Skeletal muscle (SM) is a contractile tissue primarily comprised of multinucleated myofibers. SM is one of the most important plastic tissues in the human body and accounts for around $40 \%$ of total body weight (Campbell and Stull, 2003; Frontera and Ochala, 2015; Kim et al., 2019). SMs contain multipotent precursor cells called muscle satellite cells (MSCs), which are localized below the basal lamina (BL) in myofibers, play vital roles in maintaining the integrity of SM, and participate in muscles regeneration via an organized myogenic program (Asakura et al., 2001). After injury, MSCs activate, proliferate, and fuse to form myofibers, which constitute the functional contractile parts of mature SM (Carlson and Faulkner, 1983; Bonilla et al., 1988; Stuelsatz et al., 2017).

\footnotetext{
Abbreviations: SM, Skeletal muscle; ECM, Extracellular matrix; MSCs, Muscle satellite cells; BL, Basal lamina; FN, Fibronectin; DGC, Dystrophin glycoprotein complex; UGC, Utrophin glycoprotein complex; DMD, Duchenne muscular dystrophy; BM, Basement membrane; UCMD, Ullrich congenital muscular dystrophy.
} 
The developmental process of multinucleated myofibers with contractile capability from MSCs is termed myogenesis, and involves cell cycle arrest, cell fusion, increases in nuclear sizes, and the peripheral localization of nuclei (Charge and Rudnicki, 2004). Myogenesis is a decidedly regulated mechanism that is determined by the co-expressions of Pax3, Pax7, and myogenicregulatory factors such as Myf5, Mrf4, MyoD, and myogenin in MSCs (Zammit and Beauchamp, 2001; Relaix et al., 2005; Baig et al., 2019; Kim et al., 2019; Lee et al., 2019).

SM supports skeletal development, aids skeletal movement, controls body temperature, and manages glucose uptake (Ahmad et al., 2018) and is composed of large numbers of long, multinucleated filaments, which are organized by extracellular matrix (ECM) (Davis et al., 2013). ECM plays important roles during wound healing, embryogenesis, and tissue repair and provides integrity and biochemical signals to cells (Govindan and Iovine, 2015; Ahmad et al., 2018) and is composed of glycoproteins like collagens, fibronectin (FN), and laminins (Frantz et al., 2010) (Figure 1). Furthermore, two major SM ECM proteins, that is, collagen and laminin, are known to be associated with myopathies. In previous studies, we explored the roles of a small number of ECM proteins like fibromodulin, matrix gla proteins, and dermatopontin during different stages of myogenesis (Lee et al., 2016; Ahmad et al., 2017; Lee et al., 2018; Kim et al., 2019) and found fibromodulin, as well as dermatopontin, is involved in the vigorous recruitment of MSCs at sites of injury, and thus, aids SM regeneration (Lee et al., 2018; Kim et al., 2019).

Secreted elements, such as diverse kinds of growth factors, are released during SM repair and are used to monitor muscle regeneration, but their roles and impacts on SM remodeling remain obscure (Karalaki et al., 2009). The transmembrane receptors send signals into cells from the ECM, and thus, initiate several cell functions, for instance survival, development, movement, and differentiation, which are important for sustaining the homeostasis (Theocharis et al., 2016). Notably, SM fibrosis arises in diabetes and muscular dystrophies and during immobilization and aging (Alnaqeeb et al., 1984; Williams and Goldspink, 1984; Berria et al., 2006; Gillies and Lieber, 2011).

In this review, we briefly describe SM and its major ECM components with emphasis on their roles in muscle-related diseases, which are generally fibrotic diseases or types of muscular dystrophy. We believe an in-depth understanding of the underlying mechanisms of ECM-related myopathies will aid the discovery of novel therapeutic options for the management of these devastating diseases.

\section{ECM Role in the Development and Function of SM}

ECM is a well-organized non-cellular environment that undergoes regular cycles of alterations, degradation, as well as reassembly. Cell-matrix communication contribute a vital role in cell adhesion and migration, and therefore, is critically important during embryonic and adult myogenesis (Goody et al., 2015). Various ECM proteins (e.g., dermatopontin, nidogen/entactin, periostin, and osteopontin) contribute to the regulations of cellmatrix communications and matrix assembly (Funanage et al., 1992; Norris et al., 2007; Kato et al., 2011; Kim et al., 2019).

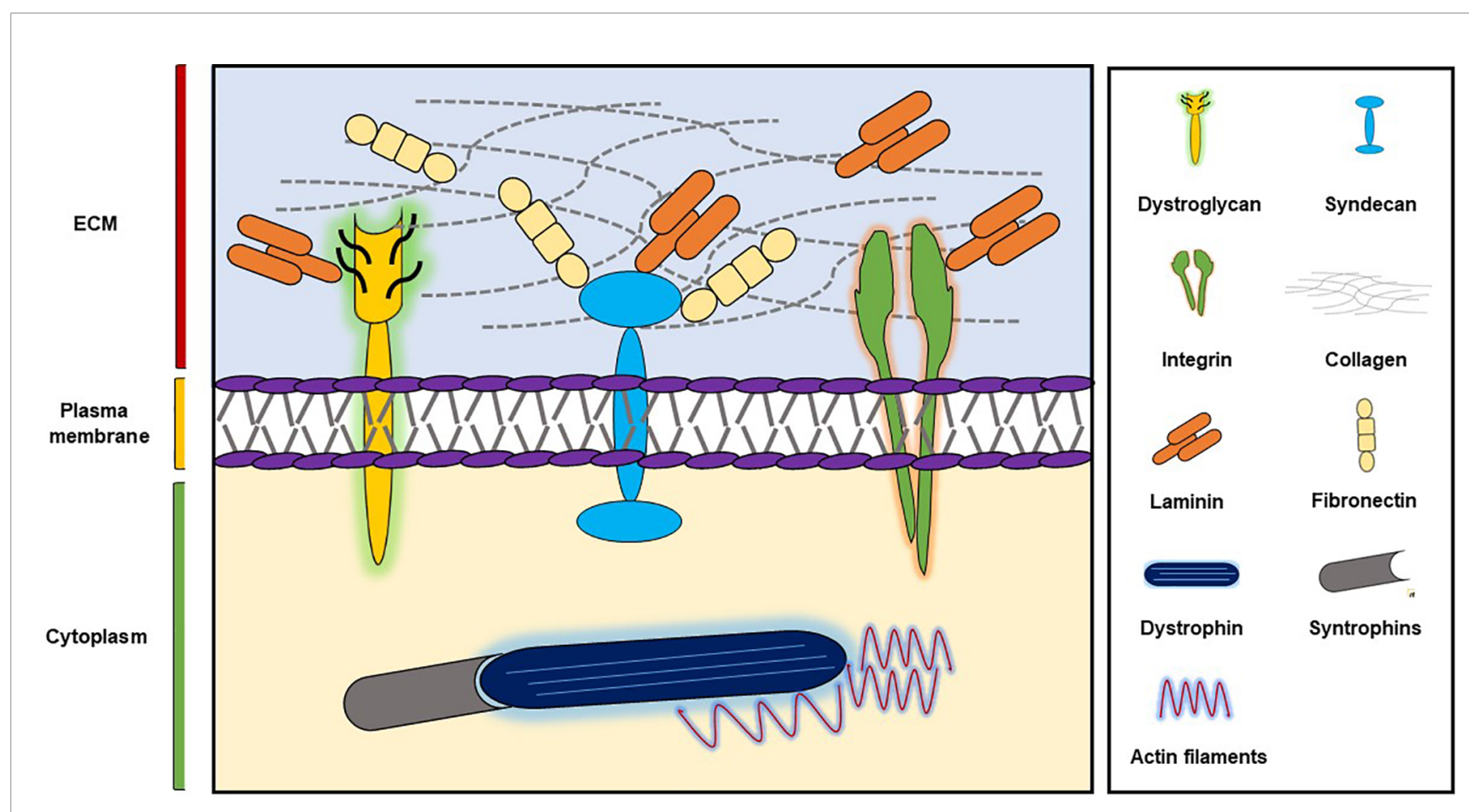

FIGURE 1 | ECM components and their major receptors. 
Myoblasts fuse to form SM fibers during the fetal stage, and myofiber numbers remain constant throughout the postnatal period. However, during this period, myofiber sizes are increased by MSC fusion. SM is among the most adaptive of body tissues, and its regenerative ability after SM injury depends on MSCs, which though generally quiescent, turn on and start to proliferate, differentiate to myoblasts, and then fused with myofibers to reestablish the contractile nature of SM after SM or MSC injury (Griffin et al., 2010).

Cross-talk between MSCs and their microenvironments determines SM regeneration. According to the MSC niche concept, the fates of stem cells are determined by stimuli arising from surrounding environments. Furthermore, MSCs exist in specific niches, consisting of muscle myofibers, muscle residence cells, vascular systems and ECM (Wilschut et al., 2010), and their functions are profoundly influenced by different microenvironments.

MSCs are enclosed in laminin and are found between muscle fibers and BL, the latter of which is composed of collagen IV and laminin networks. MSCs bind to these components using integrin receptors (Sanes, 2003), which are heterodimeric transmembrane receptors that critically transform extracellular signals into intracellular responses and interact with ECM as directed by intracellular changes (Askari et al., 2009). BL also functions as a mechanical barrier that prevents MSC migratory loss from normal SM and it might also be involved in the inhibition of MSC differentiation in the absence of damage (Sanes, 2003).

Almost all myofibers in SM develop from somites, that is, from mesodermal structures that evolve in the early embryonic segmentation (Christ and Ordahl, 1995; Pourquie, 2001). FN and its communication with integrin play vital roles during somatic cell polarization and guidance (Ostrovsky et al., 1983; Lash et al., 1985). Furthermore, decorin has been found to participate in SM development by inhibiting myostatin activity, and thus, enhancing myogenic cell proliferation and differentiation (Kishioka et al., 2008).

\section{Major Components of Muscle ECM}

The ECM is comprised of various proteoglycans and fibrous proteins (e.g., collagens, elastins, FN, and laminins). Collagen is the main structural protein in SM ECM and holds 1 to $10 \%$ of SM dry weight (Dransfield, 1977; Gillies and Lieber, 2011). The two main ECM types are: 1) interstitial matrices-connective tissue matrices comprised of mixtures of collagens, elastins, FN, proteoglycans, and glycosaminoglycans (Florin et al., 2004), and 2) pericellular matrices-which interact with cells and have more diverse molecular compositions than surrounding interstitial matrix (Thorsteinsdottir et al., 2011).

ECM represents up to $10 \%$ of muscle weight and can be classified as endomysium, perimysium, or epimysium. The endomysium contains individual myofibril, whereas the perimysium partitions SMs into fascicles, and outer support to whole SM is provided by the epimysium (Kjaer, 2004). Type I collagen has been reported to be the predominant perimysial collagen, while type III collagen is dispersed between endomysium and epimysium (Light and Champion, 1984). BMs are predominantly comprised of laminins, collagen type IV, nidogen (entactin), and perlecan (Lebleu et al., 2007), whereas collagen types VI, XV, and XVIII are also present in the BMs of SM (Halfter et al., 1998). Reticular lamina, present beneath BM, is mostly comprised of collagen fibrils (types I, III and VI) and FN in a proteoglycan rich gel (Garg and Boppart, 2016).

Laminin, collagen IV, nidogen/entactin, agrin, biglycan, and perlecan form the BL that surrounds SM fibers (Gullberg et al., 1999; Tunggal et al., 2000; Jimenez-Mallebrera et al., 2005), and it has been proposed laminin in ECM stimulates myoblast proliferation and differentiation (Rooney et al., 2009). Laminin211 is the predominent laminin isoform in BMs of adult SM (Ehrig et al., 1990; Sasaki et al., 2002), and integrins and nonintegrins are two potential groups of laminin-211 receptors. Integrins are $\alpha \beta$ heterodimeric transmembrane proteins with a huge number of functions that include adhesion, migration, and differentiation (Hynes, 2002). $\alpha 7 \beta 1$ is the major integrin of adult SM (Song et al., 1992; Burkin and Kaufman, 1999), and $\alpha$ dystroglycan is the primary non-integrin cell surface receptor (Ahmad et al., 2018). The integrins $\alpha 1 \beta 1, \alpha 2 \beta 2, \alpha 3 \beta 1, \alpha 6 \beta 1$, $\alpha 6 \beta 4, \alpha 7 \beta 1, \alpha 9 \beta 1, \alpha v \beta 3$, and $\alpha M \beta 2$ are reported to bind laminin, and most recognize the globular domain of its long arm (Wondimu et al., 2004; Tzu and Marinkovich, 2008; Durbeej, 2010). However, only $\alpha 3 \beta 1, \alpha 6 \beta 1, \alpha 6 \beta 4$ and $\alpha 7 \beta 1$ integrin are considered highly selective laminin receptors (Humphries et al., 2006; Nishiuchi et al., 2006; Barczyk et al., 2010).

Proteoglycans in SM ECM predominantly belong to the small leucine-rich proteoglycan family, and the commonly found proteoglycans in SM ECM are chondroitin sulfate and dermatan sulfate glycosaminoglycans (Brandan and Inestrosa, 1987). Furthermore, interactions between proteoglycans and collagen sustain ECM structure and organization. Proteoglycans bind to collagen at particular positions (Pringle and Dodd, 1990), and thus, proteoglycan to collagen ratios vary in ECM. In addition, the leucine-rich repeats of decorin bind with collagen type I to determine the role of decorin as a regulator of collagen fibrillogenesis in SM (Gillies and Lieber, 2011).

\section{Myopathies and ECM}

Myopathy refers to muscle diseases in which muscle weakness due to muscle fiber dysfunction is the primary symptom. Other symptoms include muscle cramps, stiffness (myotonia), and spasm. Myopathies are broadly categorized as inherited and/or acquired (Stenzel and Schoser, 2017). Inherited myopathies predominantly affect SM tissues and are generally caused by mutations in the genes responsible for SM development, as exemplified by different types of nondystrophic and dystrophic SM disorders, which manifest an extensive range of genetic and biochemical features. Muscular dystrophies, congenital metabolic myopathies, and myotonia are the most prevalent inherited myopathies (Cardamone et al., 2008; González-Jamett et al., 2018). Common muscle cramps are categorized as an acquired myopathy, for example; hypothyroid and hyperthyroid myopathies are caused by thyroid gland abnormalities (Ruff and Weissmann, 1988; Sindoni et al., 2016). Other systemic diseases (e.g., endocrine disorders, pituitary or adrenal dysfunction, 
Cushing's disease, sarcoidosis, diabetes mellitus, mixed connective disease, and electrolyte imbalance) and toxic myopathies caused by medications are also examples of acquired myopathies (Chawla, 2011). Furthermore, SM myopathies have major effects on pathogenesis and clinical outcomes may result in cardiac arrest (Chapleau, 2014).

Several human diseases are associated with ECM abnormalities, and ECM components are implicated in the pathologies of disorders that affect almost every organ system. These ECM-linked diseases are generally attributable to factors ranging from abnormal signaling functions to inadequacies of the structural components of vital organs (Iozzo and Gubbiotti, 2018). Several SM-associated genetic disorders are typically caused by mutations in ECM elements and cell surface receptors. Interestingly, more than $150 \mathrm{ECM}$ proteins have been reported to interact with integrin receptors (Zaidel-Bar et al., 2007; Ahmad et al., 2018).

The main ECM transmembrane receptor of SM is composed of dystrophin-glycoprotein complex (DGC), utrophin glycoprotein complex (UGC), and $\alpha 7 \beta 1$ integrin complex. These laminin-binding protein complexes can transform the progression of disease, and thus, are viewed as curative targets for disease intervention (Van Ry et al., 2017). $\alpha 7 \beta 1$ integrin is a laminin receptor found on the exterior surfaces of skeletal myoblasts and myofibers. In Duchenne muscular dystrophy (DMD), articulation of $\alpha 7 \beta 1$-mediated ECM binding may compensate for the absence of the dystrophin-mediated linkage. Collagen and laminin related dystrophies are typical of the diseases associated with these SM receptors (Figure 2).

In addition, the downregulation of integrin articulation may add to the progression of congenital laminin deficiencies (Burkin and Kaufman, 1999). Dystrophin is related to a muscle membrane (sarcolemmal) glycoprotein complex, which provides linkage with laminin. Interestingly, in the absence of dystrophin-related proteins (43DAG, 50DAG, 59DAP, 35DAG, and 156DAG) were markedly downregulated in the sarcolemma of DMD patients and MDX mice (Matsumura et al., 1992).

\section{Collagen Myopathy}

Collagens are the most common and major component of ECM and are reported in almost all connective tissues. They fulfill a number of critical functions in SM including the transmission of forces to bones, tensile strength, and elasticity, and are also involved in the regulations of cell attachment and differentiation. Collagens also play critical roles in cell-to-ECM interactions via several transmembrane receptors. Collagen type VI (COL VI) is a component of SM ECM in terms of these interactions (Jobsis et al., 1996).

Collagen VI is consist of $\alpha 1, \alpha 2$, and $\alpha 3$ chains, which are encoded by COL6A1 and COL6A2 on chromosome 21q22 and by COL6A3 on 2q37, respectively (Allamand et al., 2011). Mutations in all three of these genes result in two main muscle disorders types, namely; 1) Ullrich congenital muscular dystrophy (UCMD) (severe phenotype) and 2) Bethlem myopathy (minor to moderate

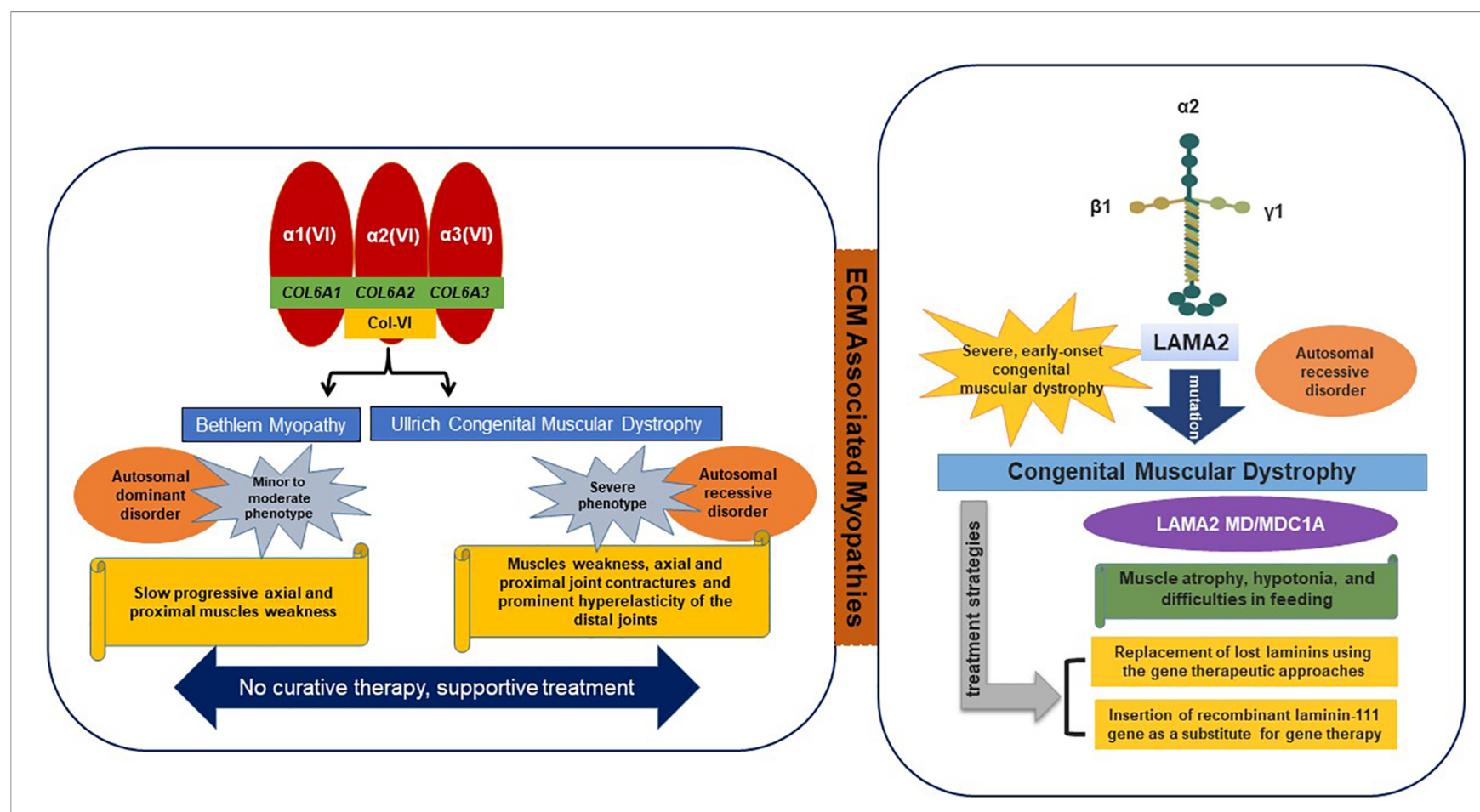

FIGURE 2 | ECM-associated myopathies. 
phenotype). Recently, two additional phenotypes were found to be associated with mutations in the COL6A2 gene, that is, limbgirdle muscular dystrophy and myosclerosis (an autosomal recessive phenotype) (Bushby et al., 2014). In ECM, collagen VI interacts with various molecules (collagen II, IV, XIV, and decorin) and cell surface receptors (fibulin 2, hyaluronan, membrane-associated chondroitin sulfate proteoglycan 4 , and biglycan) (Bonnemann, 2011).

\section{Ullrich Congenital Muscular Dystrophy (UCMD)}

UCMD is usually defined as an autosomal recessive condition that results in muscle weakness, contractures of proximal joints, and prominent hyperelasticity of distal joints (Lampe and Bushby, 2005). The UCMD phenotype is caused by loss-offunction mutations or dominant missense mutations involving glycine substitutions in the triple helical (Gly-Xaa-Yaa) motif or dominant exon-skipping mutations (Lampe and Bushby, 2005; Lampe et al., 2008). Mutations in the COL6A2 gene and more recently in the COL6A3 gene have been shown to cause UCMD (Demir et al., 2002). Usually, walking is delayed in affected children and they are unable to jump or run properly (Camacho Vanegas et al., 2001).

\section{Bethlem Myopathy}

Bethlem myopathy is a dominantly congenital, comparatively mild disease caused by mutations in the COL6A1, COL6A2, or COL6A3 genes characterized by progressive proximal muscle weakness and contractures (joint stiffness) of fingers, wrists, elbows, and ankles. Symptoms may be observed before birth due to reduced fetal movement, in early childhood due to late motor skill development, and in adults due to contractures of Achilles tendons or fingers (Lampe and Bushby, 2005; Baker et al., 2007).

The benchmark for the diagnosis of collagen myopathies is the identification of mutations in the COL6A1, COL6A2, or COL6A3 genes. Diagnoses of UCMD and Bethlem myopathy generally depend on distinctive clinical topographies in combination with mildly increased or normal levels of serum creatine kinase. Muscle biopsy is used to differentiate Bethlem myopathy and UCMD, for example, in Bethlem myopathy collagen VI immunolabeling of $\mathrm{BL}$ and endomysium are typically normal but in UCMD they are absent to obviously reduced (Lampe and Bushby, 2005). Treatments of Bethlem myopathy and UCMD involve supportive care following identical philosophies based on considerations of age at onset and observed symptom severity (Allamand et al., 2011).

Obstructive lung disease is common in patients with Bethlem myopathy and carries the risk of subsequent respiratory inadequacy (Bonnemann, 2011).

\section{Laminin Myopathy}

The laminin- $\alpha 2$ subunit is encoded by the LAMA2 gene and is primarily expressed in SM, and laminin-211 is the most abundant isoform found in BMs. Mutations in LAMA2 result in the most common types of congenital muscular dystrophies, that is, LAMA2 MD or MDC1A (Congenital type 1A), which are characterized by disruption of laminin-211 and account for 10$30 \%$ of reported cases (Sframeli et al., 2017; Mohassel et al., 2018). In general, the common symptoms of laminin myopathy are hypotonia, muscle weakness, and feeding difficulties, though joint contractures, including contractures of fingers and ankles, typically develop in later stage disease. The therapeutic strategies for LAMA $2 \mathrm{MD}$ include replacement of lost laminins using gene therapeutic approaches or the administration of recombinant laminin-111 (Yurchenco et al., 2018). In addition to binding with typical receptors (integrins and dystroglycans), laminins bind with other ECM macromolecules such as nidogens and perlecan (Carmignac and Durbeej, 2012).

\section{CONCLUDING REMARKS}

SM is greatly influenced by ECM composition, and collagen is one of the main structural proteins in ECM. ECM myopathy is a group of genetic disorders caused by mutations in genes encoding proteins that provide critical associations between the ECM and muscle cells, and UCMD and Bethlem myopathy are the main SM diseases caused by mutation of collagen VI. Laminin largely composes the BL that surrounds muscle fibers, and laminin-211 plays a crucial role in SM function. LAMA2 MD and MDC1A are destructive muscular dystrophies caused by laminin $\alpha 2$ chain loss and have no cure. The discovery of additional information related to collagen VI and laminin 211 in human SM may prove to be decisive in terms of the developments of future therapies. The objective of this article was to improve understanding by exploring relations between ECM components and related diseases so as to aid the development of effective treatments. We recommend further research work be conducted to characterize ECMrelated myopathies more precisely.

\section{AUTHOR CONTRIBUTIONS}

KA, SS, and SA wrote the initial draft of the paper and designed the figures. EL contributed to the systematic review of the literature. IC critically analyzed and approved the paper.

\section{FUNDING}

This research was supported by the National Research Foundation of Korea (NRF) funded by the Korean government (MSIP: Grant No. NRF-2018R1A2B6001020) and a grant from the NextGeneration BioGreen 21 Program (Project No. PJ01324701), Rural Development Administration, Republic of Korea. 


\section{REFERENCES}

Ahmad, S., Jan, A. T., Baig, M. H., Lee, E. J., and Choi, I. (2017). Matrix gla protein: an extracellular matrix protein regulates myostatin expression in the muscle developmental program. Life Sci. 172, 55-63. doi: 10.1016/ j.lfs.2016.12.011

Ahmad, K., Lee, E. J., Moon, J. S., Park, S. Y., and Choi, I. (2018). Multifaceted interweaving between extracellular matrix, insulin resistance, and skeletal muscle. Cells 7 (10), 148. doi: 10.3390/cells7100148

Allamand, V., Brinas, L., Richard, P., Stojkovic, T., Quijano-Roy, S., and Bonne, G. (2011). ColVI myopathies: where do we stand, where do we go? Skelet. Muscle 1, 30. doi: 10.1186/2044-5040-1-30

Alnaqeeb, M. A., Al Zaid, N. S., and Goldspink, G. (1984). Connective tissue changes and physical properties of developing and ageing skeletal muscle. J. Anat. 139 (Pt 4), 677-689.

Asakura, A., Rudnicki, M. A., and Komaki, M. (2001). Muscle satellite cells are multipotential stem cells that exhibit myogenic, osteogenic, and adipogenic differentiation. Differentiation 68, 245-253. doi: 10.1046/j.1432-0436. 2001.680412.x

Askari, J. A., Buckley, P. A., Mould, A. P., and Humphries, M. J. (2009). Linking integrin conformation to function. J. Cell Sci. 122, 165-170. doi: 10.1242/ jcs.018556

Baig, M. H., Rashid, I., Srivastava, P., Ahmad, K., Jan, A. T., Rabbani, G., et al. (2019). NeuroMuscleDB: a database of genes associated with muscle development, neuromuscular diseases, ageing, and neurodegeneration. Mol. Neurobiol. 56 (8), 5835-5843. doi: 10.1007/s12035-019-1478-5

Baker, N. L., Morgelin, M., Pace, R. A., Peat, R. A., Adams, N. E., Gardner, R. J., et al. (2007). Molecular consequences of dominant Bethlem myopathy collagen VI mutations. Ann. Neurol. 62, 390-405. doi: 10.1002/ana.21213

Barczyk, M., Carracedo, S., and Gullberg, D. (2010). Integrins. Cell Tissue Res. 339, 269-280. doi: 10.1007/s00441-009-0834-6

Berria, R., Wang, L., Richardson, D. K., Finlayson, J., Belfort, R., Pratipanawatr, T., et al. (2006). Increased collagen content in insulin-resistant skeletal muscle. Am. J. Physiol. Endocrinol. Metab. 290, E560-E565. doi: 10.1152/ ajpendo.00202.2005

Bonilla, E., Samitt, C. E., Miranda, A. F., Hays, A. P., Salviati, G., Dimauro, S., et al. (1988). Duchenne muscular dystrophy: deficiency of dystrophin at the muscle cell surface. Cell 54, 447-452. doi: 10.1016/0092-8674(88)90065-7

Bonnemann, C. G. (2011). The collagen VI-related myopathies: muscle meets its matrix. Nat. Rev. Neurol. 7, 379-390. doi: 10.1038/nrneurol.2011.81

Brandan, E., and Inestrosa, N. C. (1987). Isolation of the heparan sulfate proteoglycans from the extracellular matrix of rat skeletal muscle. J. Neurobiol. 18, 271-282. doi: 10.1002/neu.480180303

Burkin, D. J., and Kaufman, S. J. (1999). The alpha7betal integrin in muscle development and disease. Cell Tissue Res. 296, 183-190. doi: 10.1007/ s004410051279

Bushby, K. M., Collins, J., and Hicks, D. (2014). Collagen type VI myopathies. Adv. Exp. Med. Biol. 802, 185-199. doi: 10.1007/978-94-007-7893-1_12

Camacho Vanegas, O., Bertini, E., Zhang, R. Z., Petrini, S., Minosse, C., Sabatelli, P., et al. (2001). Ullrich scleroatonic muscular dystrophy is caused by recessive mutations in collagen type VI. Proc. Natl. Acad. Sci. U. S. A 98, 7516-7521. doi: $10.1073 /$ pnas. 121027598

Campbell, K. P., and Stull, J. T. (2003). Skeletal muscle basement membranesarcolemma-cytoskeleton interaction minireview series. J. Biol. Chem. 278, 12599-12600. doi: 10.1074/jbc.R300005200

Cardamone, M., Darras, B. T., and Ryan, M. M.. (2008) "Inherited myopathies and muscular dystrophies," in Seminars in neurology (Thieme Medical Publishers) 28 (2), 250-259.

Carlson, B. M., and Faulkner, J. A. (1983). The regeneration of skeletal muscle fibers following injury: a review. Med. Sci. Sports Exerc. 15, 187-198. doi: 10.1249/00005768-198315030-00003

Carmignac, V., and Durbeej, M. (2012). Cell-matrix interactions in muscle disease. J. Pathol. 226, 200-218. doi: 10.1002/path.3020

Chapleau, M. W. (2014). Contributions of skeletal muscle myopathy to heart failure: novel mechanisms and therapies. Introduction. Exp. Physiol. 99, 607608. doi: 10.1113/expphysiol.2013.074294
Charge, S. B., and Rudnicki, M. A. (2004). Cellular and molecular regulation of muscle regeneration. Physiol. Rev. 84, 209-238. doi: 10.1152/ physrev.00019.2003

Chawla, J. (2011). Stepwise approach to myopathy in systemic disease. Front. Neurol. 2, 49. doi: 10.3389/fneur.2011.00049

Christ, B., and Ordahl, C. P. (1995). Early stages of chick somite development. Anat. Embryol. (Berl) 191, 381-396. doi: 10.1007/BF00304424

Davis, M. E., Gumucio, J. P., Sugg, K. B., Bedi, A., and Mendias, C. L. (2013). MMP inhibition as a potential method to augment the healing of skeletal muscle and tendon extracellular matrix. J. Appl. Physiol. (1985) 115, 884-891. doi: 10.1152/ japplphysiol.00137.2013

Demir, E., Sabatelli, P., Allamand, V., Ferreiro, A., Moghadaszadeh, B., Makrelouf, M., et al. (2002). Mutations in COL6A3 cause severe and mild phenotypes of Ullrich congenital muscular dystrophy. Am. J. Hum. Genet. 70, 1446-1458. doi: 10.1086/ 340608

Dransfield, E. (1977). Intramuscular composition and texture of beef muscles. J. Sci. Food Agric. 28, 833-842. doi: 10.1002/jsfa.2740280910

Durbeej, M. (2010). Laminins. Cell Tissue Res. 339, 259-268. doi: 10.1007/s00441009-0838-2

Ehrig, K., Leivo, I., Argraves, W. S., Ruoslahti, E., and Engvall, E. (1990). Merosin, a tissue-specific basement membrane protein, is a laminin-like protein. Proc. Natl. Acad. Sci. U. S. A 87, 3264-3268. doi: 10.1073/pnas.87.9.3264

Florin, L., Alter, H., Grone, H. J., Szabowski, A., Schutz, G., and Angel, P. (2004). Cre recombinase-mediated gene targeting of mesenchymal cells. Genesis 38, 139-144. doi: 10.1002/gene.20004

Frantz, C., Stewart, K. M., and Weaver, V. M. (2010). The extracellular matrix at a glance. J. Cell Sci. 123, 4195-4200. doi: 10.1242/jcs.023820

Frontera, W. R., and Ochala, J. (2015). Skeletal muscle: a brief review of structure and function. Calcif Tissue Int. 96, 183-195. doi: 10.1007/s00223014-9915-y

Funanage, V. L., Smith, S. M., and Minnich, M. A. (1992). Entactin promotes adhesion and long-term maintenance of cultured regenerated skeletal myotubes. J. Cell Physiol. 150, 251-257. doi: 10.1002/jcp.1041500205

Garg, K., and Boppart, M. D. (2016). Influence of exercise and aging on extracellular matrix composition in the skeletal muscle stem cell niche. $J$. Appl. Physiol. (1985) 121, 1053-1058. doi: 10.1152/japplphysiol. 00594.2016

Gillies, A. R., and Lieber, R. L. (2011). Structure and function of the skeletal muscle extracellular matrix. Muscle Nerve 44, 318-331. doi: 10.1002/ mus. 22094

González-Jamett, A. M., Bevilacqua, J. A., and Díaz, A. M. C. (2018). "Hereditary Myopathies" in Muscle Cell and Tissue - Current Status of Research Field. Ed. K. Sakuma (IntechOpen). doi: 10.5772/intechopen.76076

Goody, M. F., Sher, R. B., and Henry, C. A. (2015). Hanging on for the ride: adhesion to the extracellular matrix mediates cellular responses in skeletal muscle morphogenesis and disease. Dev. Biol. 401, 75-91. doi: 10.1016/ j.ydbio.2015.01.002

Govindan, J., and Iovine, M. K. (2015). Dynamic remodeling of the extra cellular matrix during zebrafish fin regeneration. Gene Expr. Patterns 19, 21-29. doi: 10.1016/j.gep.2015.06.001

Griffin, C. A., Apponi, L. H., Long, K. K., and Pavlath, G. K. (2010). Chemokine expression and control of muscle cell migration during myogenesis. J. Cell Sci. 123, 3052-3060. doi: 10.1242/jcs.066241

Gullberg, D., Tiger, C. F., and Velling, T. (1999). Laminins during muscle development and in muscular dystrophies. Cell Mol. Life Sci. 56, 442-460 doi: 10.1007/PL00000616

Halfter, W., Dong, S., Schurer, B., and Cole, G. J. (1998). Collagen XVIII is a basement membrane heparan sulfate proteoglycan. J. Biol. Chem. 273, 2540425412. doi: 10.1074/jbc.273.39.25404

Humphries, J. D., Byron, A., and Humphries, M. J. (2006). Integrin ligands at a glance. J. Cell Sci. 119, 3901-3903. doi: 10.1242/jcs.03098

Hynes, R. O. (2002). Integrins: bidirectional, allosteric signaling machines. Cell 110, 673-687. doi: 10.1016/S0092-8674(02)00971-6

Iozzo, R. V., and Gubbiotti, M. A. (2018). Extracellular matrix: The driving force of mammalian diseases. Matrix Biol. 71-72, 1-9. doi: 10.1016/j.matbio. 2018.03 .023 
Jimenez-Mallebrera, C., Brown, S. C., Sewry, C. A., and Muntoni, F. (2005). Congenital muscular dystrophy: molecular and cellular aspects. Cell Mol. Life Sci. 62, 809-823. doi: 10.1007/s00018-004-4510-4

Jobsis, G. J., Keizers, H., Vreijling, J. P., De Visser, M., Speer, M. C., Wolterman, R. A., et al. (1996). Type VI collagen mutations in Bethlem myopathy, an autosomal dominant myopathy with contractures. Nat. Genet. 14, 113-115. doi: 10.1038/ ng0996-113

Karalaki, M., Fili, S., Philippou, A., and Koutsilieris, M. (2009). Muscle regeneration: cellular and molecular events. In Vivo 23, 779-796.

Kato, A., Okamoto, O., Ishikawa, K., Sumiyoshi, H., Matsuo, N., Yoshioka, H., et al. (2011). Dermatopontin interacts with fibronectin, promotes fibronectin fibril formation, and enhances cell adhesion. J. Biol. Chem. 286, 14861-14869. doi: $10.1074 /$ jbc.M110.179762

Kim, T., Ahmad, K., Shaikh, S., Jan, A. T., Seo, M. G., Lee, E. J., et al. (2019). Dermatopontin in skeletal muscle extracellular matrix regulates myogenesis. Cells 8 (4), 332. doi: 10.3390/cells8040332

Kishioka, Y., Thomas, M., Wakamatsu, J., Hattori, A., Sharma, M., Kambadur, R., et al. (2008). Decorin enhances the proliferation and differentiation of myogenic cells through suppressing myostatin activity. J. Cell Physiol. 215, 856-867. doi: $10.1002 /$ jcp. 21371

Kjaer, M. (2004). Role of extracellular matrix in adaptation of tendon and skeletal muscle to mechanical loading. Physiol. Rev. 84, 649-698. doi: 10.1152/ physrev.00031.2003

Lampe, A. K., and Bushby, K. M. (2005). Collagen VI related muscle disorders. J. Med. Genet. 42, 673-685. doi: 10.1136/jmg.2002.002311

Lampe, A. K., Zou, Y., Sudano, D., O'brien, K. K., Hicks, D., Laval, S. H., et al. (2008). Exon skipping mutations in collagen VI are common and are predictive for severity and inheritance. Hum. Mutat. 29, 809-822. doi: 10.1002/ humu.20704

Lash, J. W., Ostrovsky, D., Mittal, B., and Sanger, J. W. (1985). Alpha actinin distribution and extracellular matrix products during somitogenesis and neurulation in the chick embryo. Cell Motil. 5, 491-506. doi: 10.1002/ cm. 970050606

Lebleu, V. S., Macdonald, B., and Kalluri, R. (2007). Structure and function of basement membranes. Exp. Biol. Med. (Maywood) 232, 1121-1129. doi: 10.3181/0703-MR-72

Lee, E. J., Jan, A. T., Baig, M. H., Ashraf, J. M., Nahm, S. S., Kim, Y. W., et al. (2016). Fibromodulin: a master regulator of myostatin controlling progression of satellite cells through a myogenic program. FASEB J. 30, 2708-2719. doi: 10.1096/fj.201500133R

Lee, E. J., Jan, A. T., Baig, M. H., Ahmad, K., Malik, A., Rabbani, G., et al. (2018). Fibromodulin and regulation of the intricate balance between myoblast differentiation to myocytes or adipocyte-like cells. FASEB J. 32, 768-781. doi: 10.1096/fj.201700665R

Lee, E. J., Shaikh, S., Choi, D., Ahmad, K., Baig, M. H., Lim, J. H., et al. (2019). Transthyretin maintains muscle homeostasis through the novel shuttle pathway of thyroid hormones during myoblast differentiation. Cells 8 (12), 1565. doi: $10.3390 /$ cells 8121565

Light, N., and Champion, A. E. (1984). Characterization of muscle epimysium, perimysium and endomysium collagens. Biochem. J. 219, 1017-1026. doi: $10.1042 / \mathrm{bj} 2191017$

Matsumura, K., Ervasti, J. M., Ohlendieck, K., Kahl, S. D., and Campbell, K. P. (1992). Association of dystrophin-related protein with dystrophinassociated proteins in $\mathrm{mdx}$ mouse muscle. Nature 360, 588-591. doi: 10.1038/360588a0

Mohassel, P., Foley, A. R., and Bonnemann, C. G. (2018). Extracellular matrixdriven congenital muscular dystrophies. Matrix Biol. 71-72, 188-204. doi: 10.1016/j.matbio.2018.06.005

Nishiuchi, R., Takagi, J., Hayashi, M., Ido, H., Yagi, Y., Sanzen, N., et al. (2006). Ligand-binding specificities of laminin-binding integrins: a comprehensive survey of laminin-integrin interactions using recombinant alpha3betal, alpha6beta1, alpha7betal and alpha6beta4 integrins. Matrix Biol. 25, 189197. doi: 10.1016/j.matbio.2005.12.001

Norris, R. A., Damon, B., Mironov, V., Kasyanov, V., Ramamurthi, A., MorenoRodriguez, R., et al. (2007). Periostin regulates collagen fibrillogenesis and the biomechanical properties of connective tissues. J. Cell Biochem. 101, 695-711. doi: $10.1002 / j c b .21224$
Ostrovsky, D., Cheney, C. M., Seitz, A. W., and Lash, J. W. (1983). Fibronectin distribution during somitogenesis in the chick embryo. Cell Differ 13, 217-223. doi: 10.1016/0045-6039(83)90092-1

Pourquie, O. (2001). Vertebrate somitogenesis. Annu. Rev. Cell Dev. Biol. 17, 311350. doi: 10.1146/annurev.cellbio.17.1.311

Pringle, G. A., and Dodd, C. M. (1990). Immunoelectron microscopic localization of the core protein of decorin near the $\mathrm{d}$ and e bands of tendon collagen fibrils by use of monoclonal antibodies. J. Histochem. Cytochem. 38, 1405-1411. doi: $10.1177 / 38.10 .1698203$

Relaix, F., Rocancourt, D., Mansouri, A., and Buckingham, M. (2005). A Pax3/ Pax7-dependent population of skeletal muscle progenitor cells. Nature 435, 948-953. doi: 10.1038/nature03594

Rooney, J. E., Gurpur, P. B., Yablonka-Reuveni, Z., and Burkin, D. J. (2009). Laminin-111 restores regenerative capacity in a mouse model for alpha7 integrin congenital myopathy. Am. J. Pathol. 174, 256-264. doi: 10.2353/ ajpath.2009.080522

Ruff, R. L., and Weissmann, J. (1988). Endocrine myopathies. Neurologic Clin. 6, 575-592. doi: 10.1016/S0733-8619(18)30862-4

Sanes, J. R. (2003). The basement membrane/basal lamina of skeletal muscle. J. Biol. Chem. 278, 12601-12604. doi: 10.1074/jbc.R200027200

Sasaki, T., Giltay, R., Talts, U., Timpl, R., and Talts, J. F. (2002). Expression and distribution of laminin alpha1 and alpha 2 chains in embryonic and adult mouse tissues: an immunochemical approach. Exp. Cell Res. 275, 185-199. doi: 10.1006/excr.2002.5499

Sframeli, M., Sarkozy, A., Bertoli, M., Astrea, G., Hudson, J., Scoto, M., et al. (2017). Congenital muscular dystrophies in the UK population: Clinical and molecular spectrum of a large cohort diagnosed over a 12-year period. Neuromuscul. Disord. 27, 793-803. doi: 10.1016/j.nmd.2017.06.008

Sindoni, A., Rodolico, C., Pappalardo, M. A., Portaro, S., and Benvenga, S. (2016). Hypothyroid myopathy: a peculiar clinical presentation of thyroid failure. review of the literature. Rev. Endocr. Metab. Disord. 17, 499-519. doi: 10.1007/ s11154-016-9357-0

Song, W. K., Wang, W., Foster, R. F., Bielser, D. A., and Kaufman, S. J. (1992). H36alpha 7 is a novel integrin alpha chain that is developmentally regulated during skeletal myogenesis. J. Cell Biol. 117, 643-657. doi: 10.1083/jcb.117.3.643

Stenzel, W., and Schoser, B. (2017). Inherited and acquired muscle weakness: a moving target for diagnostic muscle biopsy. Neuropediatrics 48, 226-232. doi: $10.1055 / \mathrm{s}-0037-1601859$

Stuelsatz, P., Keire, P., and Yablonka-Reuveni, Z. (2017). Isolation, culture, and immunostaining of skeletal muscle myofibers from wildtype and Nestin-GFP mice as a means to analyze satellite cell. Methods Mol. Biol. 1556, 51-102. doi: 10.1007/978-1-4939-6771-1_4

Theocharis, A. D., Skandalis, S. S., Gialeli, C., and Karamanos, N. K. (2016). Extracellular matrix structure. Adv. Drug Delivery Rev. 97, 4-27. doi: 10.1016/ j.addr.2015.11.001

Thorsteinsdottir, S., Deries, M., Cachaco, A. S., and Bajanca, F. (2011). The extracellular matrix dimension of skeletal muscle development. Dev. Biol. 354, 191-207. doi: 10.1016/j.ydbio.2011.03.015

Tunggal, P., Smyth, N., Paulsson, M., and Ott, M. C. (2000). Laminins: structure and genetic regulation. Microsc. Res. Tech. 51, 214-227. doi: 10.1002/10970029(20001101)51:3<214::AID-JEMT2>3.0.CO;2-J

Tzu, J., and Marinkovich, M. P. (2008). Bridging structure with function: structural, regulatory, and developmental role of laminins. Int. J. Biochem. Cell Biol. 40, 199-214. doi: 10.1016/j.biocel.2007.07.015

Van Ry, P. M., Fontelonga, T. M., Barraza-Flores, P., Sarathy, A., Nunes, A. M., and Burkin, D. J. (2017). ECM-related myopathies and muscular dystrophies: pros and cons of protein therapies. Compr. Physiol. 7, 1519-1536. doi: 10.1002/cphy.c150033

Williams, P. E., and Goldspink, G. (1984). Connective tissue changes in immobilised muscle. J. Anat. 138 (Pt 2), 343-350.

Wilschut, K. J., Haagsman, H. P., and Roelen, B. A. (2010). Extracellular matrix components direct porcine muscle stem cell behavior. Exp. Cell Res. 316, 341352. doi: 10.1016/j.yexcr.2009.10.014

Wondimu, Z., Geberhiwot, T., Ingerpuu, S., Juronen, E., Xie, X., Lindbom, L., et al. (2004). An endothelial laminin isoform, laminin 8 (alpha4betalgamma1), is secreted by blood neutrophils, promotes neutrophil migration and extravasation, and protects neutrophils from apoptosis. Blood 104, 18591866. doi: 10.1182/blood-2004-01-0396 
Yurchenco, P. D., Mckee, K. K., Reinhard, J. R., and Ruegg, M. A. (2018). Laminin-deficient muscular dystrophy: Molecular pathogenesis and structural repair strategies. Matrix Biol. 71-72, 174-187. doi: 10.1016/ j.matbio.2017.11.009

Zaidel-Bar, R., Itzkovitz, S., Ma'ayan, A., Iyengar, R., and Geiger, B. (2007). Functional atlas of the integrin adhesome. Nat. Cell Biol. 9, 858-867. doi: 10.1038/ncb0807-858

Zammit, P., and Beauchamp, J. (2001). The skeletal muscle satellite cell: stem cell or son of stem cell? Differentiation 68, 193-204. doi: 10.1046/j.14320436.2001.680407.x
Conflict of Interest: The authors declare that the research was conducted in the absence of any commercial or financial relationships that could be construed as a potential conflict of interest.

Copyright (c) 2020 Ahmad, Shaikh, Ahmad, Lee and Choi. This is an open-access article distributed under the terms of the Creative Commons Attribution License (CC $B Y$ ). The use, distribution or reproduction in other forums is permitted, provided the original author(s) and the copyright owner(s) are credited and that the original publication in this journal is cited, in accordance with accepted academic practice. No use, distribution or reproduction is permitted which does not comply with these terms. 